\title{
Abundance, movements and biodiversity of flying predatory insects in crop and non-crop agroecosystems
}

\author{
Juan Sorribas $^{1}$ - Sandra González ${ }^{2}$ - Alfons Domínguez-Gento ${ }^{3} \cdot$ Rosa Vercher $^{2}$
}

Accepted: 22 March 2016/Published online: 4 May 2016

(C) INRA and Springer-Verlag France 2016

\begin{abstract}
Predatory insects are key natural enemies that can highly reduce crops pest damage. However, there is a lack of knowledge about the movements of flying predatory insects in agroecosystems throughout the year. In particular, it is still unclear how these predators move from crop to non-crop habitats, which are the preferred habitats to overwinter and to spread during the spring and if these predators leave or stay after chemical treatments. Here, the Neuroptera, a generalist, highly mobile, flying predator order of insects, was selected as model. We studied the effects of farming management and the efficiency of edge shelterbelts, ground cover vegetation, and fruit trees canopy on holding flying predatory insects in Mediterranean traditional agroecosystems. Seasonal movements and winter effects were also assessed. We evaluated monthly nine fruit agroecosystems, six organic, and three pesticides sprayed, of $0.5-1$ ha in eastern Spain during 3 years using two complementary methods, yellow sticky traps and
\end{abstract}

Juan Sorribas

juasorme@gmail.com

Sandra González

sangonc1@upvnet.upv.es

Alfons Domínguez-Gento

dominguez_alf@gva.es

Rosa Vercher

rvercher@eaf.upv.es

1 ECOBIO Institute-Université de Rennes1, UMR 6553, Avenue du Général Leclerc. Campus de Beaulieu, F-35042 Rennes, France

2 Instituto Agroforestal Mediterráneo - IAM, Universidad Politécnica de Valencia, Camino de Vera s/n, 46022 Valencia, Spain

3 Estació Experimental Agrària de Carcaixent, Valencian Institute for Agricultural Research (IVIA), Valencia, Spain aspirator. Results show surprisingly that the insect abundance was highest in pesticide sprayed systems, with 3.40 insects/ sample versus 2.32 insects/sample in organic systems. The biodiversity indices were highest in agroecosystems conducted under organic management, with S of 4.68 and $\mathrm{D}$ of 2.34. Shelterbelts showed highest biodiversity indices, S of 3.27 and D of 1.93, among insect habitats. Insect species whose adults were active during the winter preferred fruit trees to spend all year round. However, numerous species moved from fruit trees to shelterbelts to overwinter and dispersed into the orchard during the following spring. The ground cover vegetation showed statistically much lower attractiveness for flying predatory insects than other habitats. Shelterbelts should therefore be the first option in terms of investment in ecological infrastructures enhancing flying predators.

Keywords Mediterranean agroecosystem · Organic management - Conservation biological control . Entomophagous arthropod $\cdot$ Shelter habitat $\cdot$ Cover crop · Neuroptera $\cdot$ Lacewing $\cdot$ Citrus $\cdot$ Spain

\section{Introduction}

An agroecosystem, the basic unit of study in agroecology, can be identified as an area which includes crop habitats and non-crop habitats adjacent to the crops (You et al. 2004). Intensive agriculture often involves a maximum utilization of the land surface which includes removal of non-crop areas such as surrounding woody vegetation (i.e., hedgerows and shelterbelts), riparian herbaceous vegetation, and weeds. Throughout Europe, the expansion of modern, chemicalintensive agriculture is regarded as the principal cause of the widespread declines in abundance and diversity of predatory 
insects over the past decades (e.g., Hole et al. 2005; Bianchi et al. 2006). Sustainable practices such as organic farming, cover cropping, and hedgerows preservation may contribute to enhance predatory insects living within agroecosystems (Altieri and Letourneau 1982; Östman et al. 2001). Because arthropod generalist predators (or entomophagous arthropods) must efficiently search for preys, they can be considered ideal models for investigating conservation techniques (Panzer and Schwartz 1998). Conservation biological control (CBC) is the practice of enhancing natural enemies through modification of the environment or landscape of an agroecosystem (Eilenberg et al. 2001). The practice of CBC, which involves the manipulation of agricultural habitats to favor the natural enemies, offers the possibility of simultaneously increasing insect and plant biodiversity and reducing pest problems (Straub et al. 2008).

Although higher biodiversity not necessarily means better biological control, conserving natural enemy species richness could increase the chances that the enemy community will contain good enemy species, leading to a positive relationship between natural enemy species richness and biological control (Straub et al. 2008). This has led to growing interest in management practices that promote on-farm biodiversity such us organic farming (e.g., Hole et al. 2005; Straub et al. 2008). In general, organic farming is reported to increase arthropod diversity in agricultural landscapes (e.g., Bengtsson et al. 2005; Hole et al. 2005; Smukler et al. 2010). Organic farming usually increases arthropod species richness and abundance, having on average $30 \%$ higher species richness and $50 \%$ more abundance than conventional farming systems (Bengtsson et al. 2005). When compared with sprayed crops, more natural enemies establish and maintain themselves in organic crops whereas arthropod herbivores usually exhibit an opposite trend (Altieri and Schmidt 1986; Östman et al. 2001).

Non-crop natural or semi-natural habitats inside agroecosystems such as field margins, grassy ground cover, hedgerows, and shelterbelts are relatively undisturbed and temporally permanent areas that may provide resources that are critical to sustaining natural enemy population diversity (Landis et al. 2000; Bianchi et al. 2006). These patches of vegetation in agricultural landscapes can enhance natural enemies by providing foods (e.g., alternate hosts for parasitoid wasps, preys for predatory insects, honeydew, pollen, or nectar), modified climate (e.g., windbreaks made by shelterbelts) and/or more niches (e.g., overwintering and nesting habitats) (e.g., Altieri and Letourneau 1982; Landis et al. 2000; Gurr et al. 2003; Bianchi et al. 2006). The abundance and diversity of predatory insects within crop fields and orchards are closely related to the surrounding vegetation (Altieri and Letourneau 1982). One of the major limitations to understand how natural enemies are affected by non-crop vegetation is knowing how they move or disperse within their environment throughout the year. Movement is critical to escape from disturbances and to find resources scattered in space and time. However, there is a lack of studies showing year-round movements of predators between croplands and surrounding areas, (see Rand et al. 2006) and the knowledge of how highly mobile flying predators overwinter in orchard agroecosystems is even lower. Flying insects are ideal models since they can escape after chemical treatments to surrounding noncrop habitats or stay in the field if they can stand to nonintensive treatments. Since non-crop habitats provide requisites for natural enemies, they may act as sinks relative to crop habitats when natural enemies have a year-round preference for these habitats thus reducing the exchange of natural enemies between crop and non-crop habitats (Bianchi et al. 2006). Appropriate landscape management in agricultural systems requires an understanding of insect seasonal movements and dispersal.

We chose a generalist, highly mobile, flying predator order of insects, Neuroptera, as model to identify the most important habitats for biodiversity conservation in Mediterranean traditional agroecosystems for flying predatory insects. Neuropters have been previously used as standard of value for generalist predators and indicators of the ecological status of rural habitats due to the susceptibility of most species to pesticides and their well-known environmental needs (e.g., Stelzl and Devetak 1999; Thierry et al. 2005). Neuropters were selected because they occupy the top of the ecological arthropod trophic pyramid, they occur in very diverse habitats all year round, they can easily displace between non-crop and crop habitats, they have different feeding abilities, they need growing vegetation to feed and lay their eggs, and they are sensitive indicators of environmental richness, stability, and local diversity (see Stelzl and Devetak 1999; Villenave et al. 2005). In commercial orchards, neuropteran populations develop only when insecticide treatment is not applied in intervals that are too short (Pantaleoni and Ticchiati 1988), and adult specimens can fly the distance between boundary vegetation and fruit trees (some marked Neuroptera species have been collected up to $200 \mathrm{~m}$ away from the marking point) (Long et al. 1998).

Here, we hypothesize the following:

a. There will be a reduction in biodiversity and abundance of natural enemies in "conventional" sprayed orchards in relation to organic managed orchards.

b. Due to the larger total area and complementary food source all year round of the ground cover vegetation (e.g., pollen from weeds with different flowering periods), it will be the preferred habitat over woodland habitats for most species.

c. Flying predators will displace from fruit tree canopies to non-crop habitats to overwinter. 


\section{Materials and methods}

\subsection{Study area}

The study was performed in the south of Valencia province (eastern Spain), an area with typical Mediterranean agroecosystems dominated by small fruit orchards of $0.5-1$ ha. The landscape of the study area is composed mostly of clementine mandarins Citrus clementina Tanaka (many of them having grassy ground cover in fruit trees understory) and patches of natural or planted native woody vegetation (shelterbelts) surrounding the orchards. This woody vegetation, which has been historically used to form a natural fence and as windbreaks, is constituted by rows of trees and tall shrubs which can be remnants of existing vegetation from cleared lands, a result of natural plant dispersal, or established via direct plantings by farmers.

We delimited habitat types according to vegetation structure (vegetation strata) and human agricultural activities. The habitat types defined were (1) fruit tree canopies, (2) ground cover vegetation (grassland), and (3) shelterbelts of woody vegetation (surrounding fruit orchards).

For the study, we selected nine plots constituting nine isolated agroecosystems; each of them formed by a citrus orchard with ground cover vegetation growing in fruit trees understory and woody shelterbelts surrounding all sides of the orchards. Plots were separated a maximum of 20 lineal kilometers and about 15-20 lineal kilometers away from the Mediterranean Sea coast.

Citrus trees inside agroecosystems of the study area were cultivated under two forms of farming practice, certified organic management (six orchards) and "conventional" sprayed management (three orchards). Insecticidal treatments for these orchards included phosphorate insecticides, pyrethroids, and acaricides which were applied twice a year under integrated pest management strategies. Both organic and sprayed orchards had been under the same farming practice for the previous 7-10 years. We analyzed and compared the biodiversity and abundance of lacewings in both groups.

Shelterbelts of the study area were rather similar and had a mixed composition of several Mediterranean native perennial trees and shrubs species, predominantly Pistacia lentiscus L., Nerium oleander L, Viburnum tinus L., and/or Phillyrea angustifolia. The distance between any of the edges and the central trees of the orchard was always lower than $100 \mathrm{~m}$ (inferior than Neuropters flying capacity). Ground vegetation was composed of spontaneous or sown herbaceous species (grass), predominantly Cynodon sp., Bromus sp., Amaranthus sp., Sonchus sp., Chenopodium sp., Senecio sp., Calendula sp., Medicago sativa L., and/or Melilotus officinalis L. Natural regeneration of ground vegetation was allowed before mowing (twice a year).

\subsection{Insect material and sampling methodology}

Neuroptera is an insect order of polyphagous predators of many agricultural pests such as mites, scales, whiteflies, and aphids (Stelzl and Devetak 1999). Almost all feeding behaviors can be found within Neuropteran families, omnivorous (Hemerobiidae and Chrysopidae), carnivorousglycinophagous (Coniopterygidae); phytophagous (some Chrysopidae), and pollino-glycinophagous (some Chrysopidae can feed on pollen from about 40 trees), and several species are mass reared and released within classical biological control programs (Stelzl and Devetak 1999; Villenave et al. 2005).

Due to its different feeding preferences and flying abilities and the diverse plant structure and architecture of the three habitats evaluated, we choose two very different sampling methods in order to maximize catches of neuropteran insects: aspiration sampling and sticky traps.

The sampling process was performed fortnightly from May to October and monthly during the cold period for this region, November to April, during three consecutive years (October 2006-October 2009). In the six organic farming orchards, three habitats were sampled: fruit tree crowns, ground cover vegetation, and orchards surrounding shelterbelts, whereas in the three conventionally managed orchards only citrus trees were sampled.

Aspiration sampling was carried out with a custom built suction machine composed of a commercial garden twostroke engine-powered leaf blower (Komatsu Zenoah Co., HBZ2601 model) assembled with a cylindrical plastic suction mouth $30 \mathrm{~cm}$ high and $30 \mathrm{~cm}$ in diameter. This is a modification of the gasoline-driven vacuum device designed by Dogramaci et al. (2011). The sampling process was standardized for an aspiration of 2 min duration (equivalent to 1-3 trees depending on size) in all cases. All sucked insects were retained in a fine mesh placed at the extreme of the suction tube. The mesh was replaced after each aspiration process, and insects captured were conserved inside the mesh which was annotated with a sample number. Sampling with the suction device was randomly performed three to four times for citrus tree canopies of each orchard, three to four times for shelterbelts, and three to four times for the ground vegetation (depending of orchard and shelterbelt size).

Yellow traps consist of a $10 \times 25 \mathrm{~cm}$ plastic rectangle with sticky surface which were vertically hanged from two to three citrus trees and from two to three hedge trees or shrubs per orchard. In the ground vegetation, two to three traps per orchard were placed on wooden posts planted in the soil at constant a height of $50 \mathrm{~cm}$ above the ground. Traps were collected and replaced the same day as the aspiration process was performed (Fig. 1).

Trees and ground surface for sampling were randomly selected for both methods. In the laboratory, all Neuroptera insects collected or trapped were observed under a 
Fig. 1 Schematic figure showing the type of habitats evaluated in this study (left side), the sampling methods (center), and the main species representing the main insect families found in this study (right side). From top to bottom: woody shelterbelts, fruit trees canopy, and ground cover vegetation (left side), yellow sticky trap and vacuum device (center), and adult specimens of Chrysopidae, Coniopterygidae and Hemerobiidae families respectively (right side)
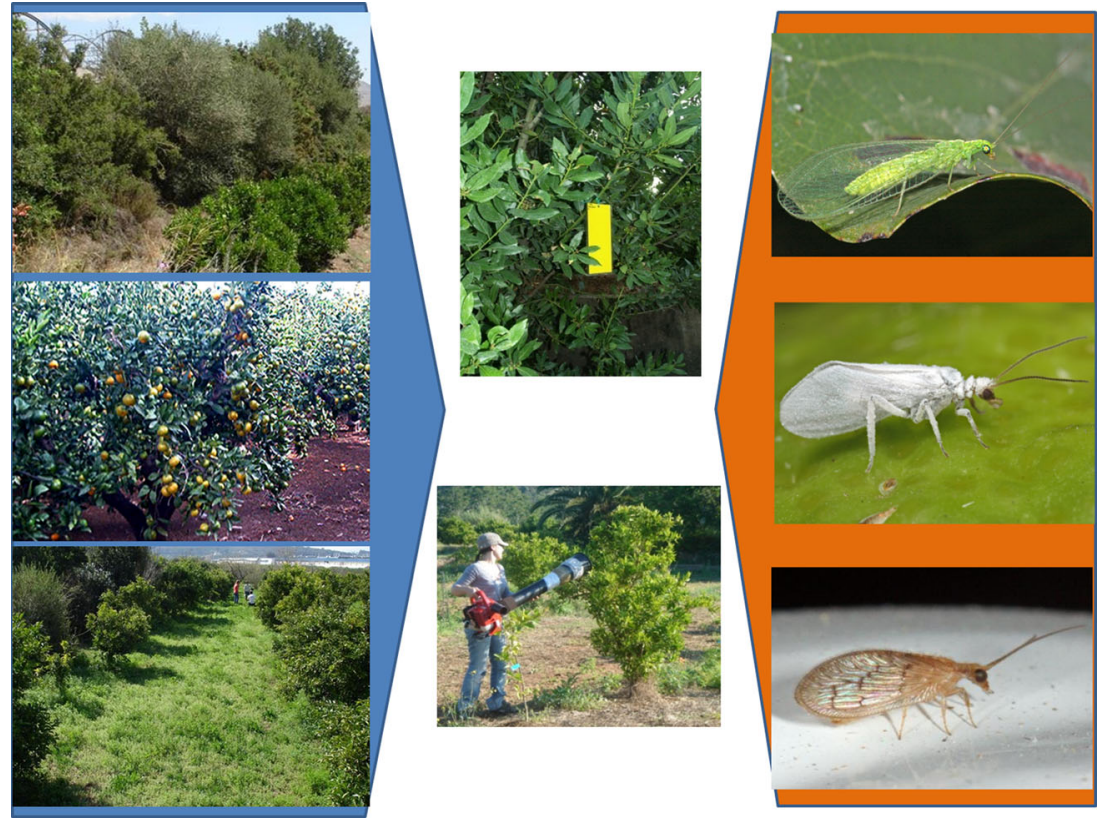

stereomicroscope and classified to species or higher taxonomic levels. The several species of the cryptic carnea group were classified into a single category hereby referred to as Chrysoperla carnea Stephens.

A total of 3302 samples were collected with the suction device and 2384 yellow sticky traps from the 6 organic agroecosystems during the 3 years. The citrus trees of sprayed agroecosystems were sampled using the suction device and yellow sticky traps following the same protocol described, with the difference that in this case only the fruit trees were sampled. A total of 346 aspiration samples and 236 yellow sticky traps were collected.

\subsection{Data analysis}

For the statistical analysis of the abundance of captures by the two sampling methods, we performed a simple analysis of variance (ANOVA) of all the data in all habitats $(8$ species and 29,177 data). For the comparative between $\mathrm{D}$ biodiversity indices and between species richness, we calculated the monthly diversity index and the number of species by summing up the total individuals captured monthly in each agroecosystem followed by ANOVA multiple range test. The comparative between abundance in organic and sprayed agroecosystems was done by simple ANOVA of all data. When we compared fruit trees, ground cover, and shelterbelts, we performed multifactor ANOVA considering year and habitat as factors for each species.

In order to evaluate the number of species and diversity indices, data were grouped monthly as number of insects or number of species/month for each year and sampling methodology. Two of the most commonly used indices were selected to quantify Neuropteran biodiversity: Taxonomic species richness [S], i.e., the number of species collected and Simpson's diversity index [D].

\section{Results and discussion}

\subsection{Relative abundance of lacewings}

The analysis of the total number of captures of all species by the two sampling methods shows that when using the suction device, lacewings of Chrysopidae family (green lacewings) were the most commonly captured $(F=166.07 ; \mathrm{df}=7,29$ 176; $P<0.0001)$ whereas yellow sticky traps captured, in general, much higher proportion of Coniopterygidae (dustywings) (97\% of the total lacewings captured with this method; $F=216.64$; df =7, 23 535; $P<0.0001)$. Chrysoperla carnea was the most frequently captured species with the aspirator whereas Semidalis aleyrodiformis Stephens was the most common Neuroptera on yellow sticky traps (more than 5000 specimens captured). The amount of Hemerobiids (brown lacewings) was small and similar with both methods. This indicates that green lacewings and dustywings have different flying or displacement strategies, and both capturing methods are complementary in order to evaluate the abundance and diversity of these flying insects.

Out of 14,318 adult lacewings collected, we identified ten species (coexisting in both organic and sprayed agroecosystems) belonging to three families. Chrysopidae (green lacewings): Ch. carnea, Chrysopa septempunctata Wesmael and two unidentified Dichochrysa species; Coniopterygidae (dustywings): S. aleyrodiformis, Conwentzia psociformis (Curt.) and 
two unidentified Coniopteryx species; Hemerobiidae (brown lacewings): Micromus angulatus Stephens and Wesmaelius subnebulosus Stephens.

When compared with Neuroptera abundance and species richness found by other authors in agroecosystems composed of arable crops (e.g., Pantaleoni and Ticchiati 1988), we observed that it was much lower than in these evergreen fruit orchards. Perennial crop systems such as fruit orchards are more stable than annual systems, and they are subject to lower levels of disturbance which could explain differences in predator abundance and biodiversity.

\subsection{Species richness and biodiversity indices}

Values reached for species richness and Simpson Diversity Index [D] were higher in fruit orchard agroecosystems conducted under organic management than in sprayed conventional agroecosystems. The mean number of species [S] captured per month was significantly higher $(F=66.13$; $\mathrm{df}=1,144 ; P<0.0001)$ in organic orchards $(4.68 \pm 0.22$ species/month) than the number in sprayed orchards $(2.33 \pm 0.18$ species/month). The same pattern was found for the biodiversity index, with the organic orchards having an average [D] of $2.35 \pm 0.09$, significantly higher $(F=20.05$; $\mathrm{df}=1,144 ; P<0.0002)$ than the sprayed orchards, $1.31 \pm 0.08$ (Fig. 2a). These outcomes agree with previous studies in other agroecosystems (see Altieri and Schmidt 1986; Bengtsson et al. 2005).

When comparing the insect biodiversity associated to each habitat type, we found that shelterbelts had the highest values for the biodiversity indices evaluated, followed by the biodiversity associated to fruit tree canopies, and lastly by ground vegetation associated insects. Biodiversity indices differences between habitat types were statistically significant (S: $F=41.70 ; \mathrm{df}=2,188$; $P<0.0001$. D: $F=26.61 ; \mathrm{df}=2,188 ; P<0.0001$ ) (Fig. $2 b$ ).

\subsection{Relative abundance in organic and sprayed agroecosystems}

When comparing organic and sprayed agroecosystems insect relative abundance (bringing together data from yellow traps and aspirator), we found some significant differences (Table 1). The total mean amount of adult Neuroptera captured in sprayed agroecosystems $(3.40 \pm 0.54$ adults/sample) was significantly higher $(F=16.51 ; \mathrm{df}=1,5943 ; P<0.001)$ than in organic agroecosystems $(2.32 \pm 0.14$ adults/sample $)$. This unexpected result was mainly due to the high level of a single dominant species, Ch. carnea, found in sprayed agroecosystems, $0.48 \pm 0.07$ adults/sample, compared to organic agroecosystems, $0.18 \pm 0.01$ adults/ sample $(\mathrm{F}=55.30 ; \mathrm{df}=1,5943 ; \mathrm{P}<0.001)$. The analysis of the population dynamics of Ch. carnea showed that a

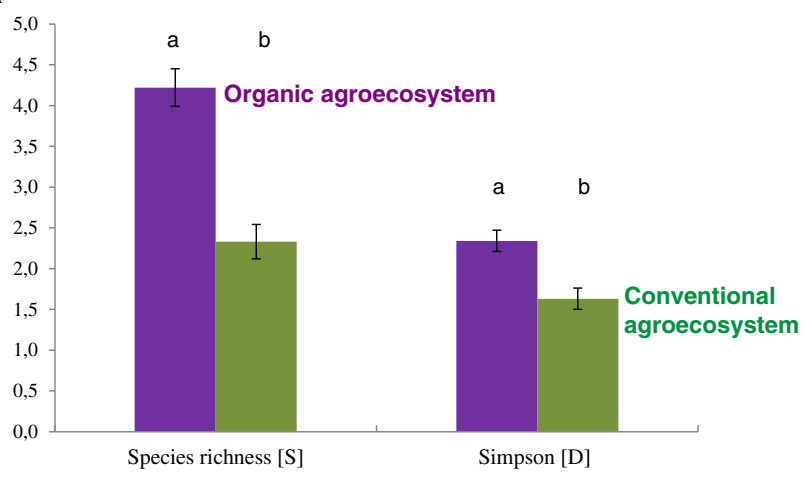

b

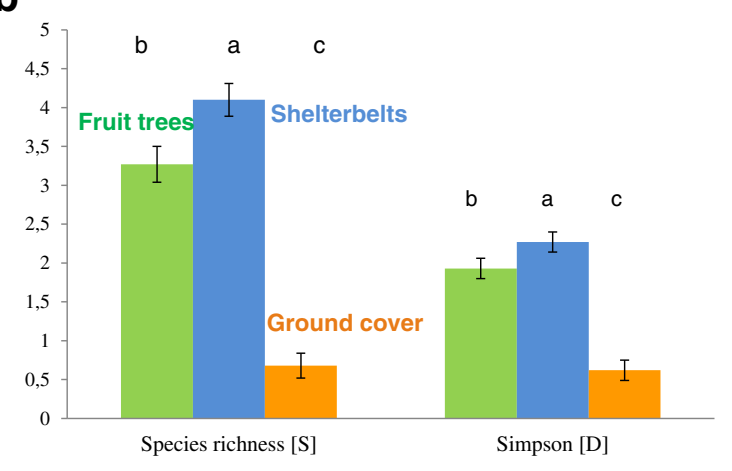

Biodiversity Index

Fig. 2 Biodiversity indices (Species richness [S] and Simpson's diversity index [D]) of a Neuropters living within fruit orchard agroecosystems under organic and sprayed (conventional) management. b Neuropters living within three habitat types: citrus trees canopy, shelterbelts, and ground cover vegetation inside fruit agroecosystems. Samples were collected using a suction device and yellow sticky traps from nine orchard agroecosystems of eastern Spain during the period 2006 to 2009. Vertical bars indicate standard error (SE) of the means. Values followed by the same letter are not significantly different from each other according to Fisher's LSD multiple range test $(P \leq 0.05)$

this species was much more abundant in agroecosystems under sprayed management during summer, while their relative abundance in organic agroecosystems remained rather stable all year round.

This implies that some species are able to resist chemical treatments up to certain degree when staggered in time. The resistance of Ch. carnea to many pesticides and the sensibility of other Neuropteran species to these pesticides was previously indicated by Stelzl and Devetak (1999). Agricultural pestmanagement practices often lead to altered food web structure and communities dominated by a few common species whereas organic farming methods mitigate this ecological damage by promoting evenness among natural enemies (Crowder et al. 2010). This could explain why Ch. carnea became the dominant species during summer in sprayed agroecosystems (end of spring was a period for chemical treatments) whereas in ecological agroecosystems the abundance of this species kept rather constant throughout the year. 
Among Coniopterygidae, no differences were found in both management systems. The more uncommon neuropters, Ch. septempunctata, M. angulatus, W. subnebulosus, and Dichochrysa species were significantly more abundant in organic agroecosystems (Table 1).

\subsection{Insect distribution inside organic agroecosystems}

Considering together captures with the aspirator and traps within the organic agroecosystems, an average of $2.31 \pm 0.21$ adult lacewings per sample was captured in citrus tree canopies, $2.51 \pm 0.19$ lacewings per sample in surrounding trees and shrubs and only $0.11 \pm 0.02$ lacewings per sample in the ground cover vegetation. Three distribution patterns were observed (Fig. 3):

- Species which were more abundant in citrus tree canopies, represented by $C$. psociformis $(F=8.77$; $\mathrm{df}=2$, 1288; $P<0.001)$ and $C h$. carnea $(F=12.38 ; \mathrm{df}=2$, 1288; $P<0.001)$;

- Species significantly more abundant in citrus tree canopies and shelterbelts than in the ground vegetation, such as $S$. aleyrodiformis $(F=12.26 ; \mathrm{df}=2,1288 ; P<0.001)$ and Coniopteryx spp. $(F=12.92 ; \mathrm{df}=2,1288 ; P<0.001)$;

- Species which were present in similar proportion in the three habitat types $(F=0.95 ; \mathrm{df}=2,1288 ; P=0.3888)$ such as Chrysopa septempunctata Wesmael.

Unexpectedly, the herbaceous ground cover vegetation showed much lower attractiveness to lacewings than the canopy of shelterbelts and fruit trees. Thus, our first hypothesis based on the supposition that lacewings would find more complementary food from the many flowering weeds of the ground vegetation, which was supported on previous studies that found high abundance of many predatory insects at ground vegetation level (e.g., Bianchi et al. 2006; Silva et al. 2010) was wrong. There may be several reasons explaining this behavior: the comparative higher disturbance at the ground vegetation level (mowing, fruit picking, etc), the better refuge against wind and extreme temperatures that shelterbelts represent (wooded habitats provide more moderate microclimate (Forman and Baudry 1984)), and/or the higher abundance of non-flying competing predators in the above ground layer (some of them can act also as predators of lacewings). This illustrates the importance of considering plant structure and architecture when evaluating predatory insect habitats. Thus, in terms of economic investment in non-crop habitats enhancing flying predators, it is clear that shelterbelts should be considered as the preferable choice when assessing alternative landscape configurations. Nevertheless, it is important to bear in mind that, as demonstrated by Paredes et al. (2013), in fruit agroecosystems there may be a positive synergistic effect between shelterbelts and ground vegetation in terms of beneficial predator abundance and diversity.

\subsection{Seasonal population dynamics}

We analyzed seasonal dynamics of the most abundant Neuroptera species from data collected with the aspirator device within the organic agroecosystems. Yellow sticky traps were not considered for this purpose since they remain in the field 1 month during the cold period.

The analysis of the three habitats evaluated allowed separating insect species in several groups (Fig. 4):

- Species that showed seasonal migration from fruit trees to shelterbelts to overwinter: Ch. septempunctata, $M$. angulatus, and W. subnebulosus. Adult populations of these species associated to citrus trees start to decline at the end of summer and beginning of autumn (September-October) at the same time that populations associated with shelterbelts increased. For these, species captures of adults during the winter period (equivalent in the case of Valencia to the "non-growing season" from
Table 1 Mean number $(\mathrm{M} \pm \mathrm{SE})$ of adult Neuroptera captured per sample in fruit agroecosystems under organic and conventional (sprayed) management. Samples were collected with a suction device and yellow sticky traps from 2006 to 2009 in agroecosystems of eastern Spain. Dichochrysa species (Chrysopidae) were not considered due to the low number of captures

\begin{tabular}{llllll}
\hline & & $\begin{array}{l}\text { Organic } \\
\text { agroecosystem } \\
\text { Family }\end{array}$ & $\begin{array}{l}\text { Conventional } \\
\text { agroecosystem } \\
\mathrm{M} \pm \mathrm{SE}\end{array}$ & $F$ & $P$ \\
\hline Chrysopidae & Chrysoperla carnea & $0.18 \pm 0.01 \mathrm{~b}$ & $0.48 \pm 0.07 \mathrm{a}$ & 55.30 & $<0.0001$ \\
& Chrysopa septempunctata & $0.07 \pm 0.005 \mathrm{a}$ & $0.03 \pm 0.01 \mathrm{~b}$ & 4.43 & 0.003 \\
Coniopterygidae & Conwentzia psociformis & $0.64 \pm 0.07 \mathrm{a}$ & $1.02 \pm 0.36 \mathrm{a}$ & 0.80 & 0.37 \\
& Semidalis aleyrodiformis & $0.92 \pm 0.09 \mathrm{a}$ & $1.22 \pm 0.26 \mathrm{a}$ & 1.07 & 0.30 \\
& Coniopteryx sp. & $0.47 \pm 0.05 \mathrm{a}$ & $0.62 \pm 0.23 \mathrm{a}$ & 0.00 & 0.98 \\
& Micromus angulatus and & $0.02 \pm 0.003 \mathrm{a}$ & $0.00 \pm 0.00 \mathrm{~b}$ & 9.40 & 0.002 \\
& Wesmaelius subnebulosus & & & &
\end{tabular}

Note: Values in rows followed by the same letter are not significantly different from each other according to Fisher's LSD multiple range test $(p \leq 0.05)$ 
Fig. 3 Occurrence of the most abundant Neuroptera species within three habitats (fruit trees, shelterbelts, and ground covers) belonging to orchard agroecosystems. Samples were collected with a suction device from 2006 to 2009 in six agroecosystems of Valencia Region (eastern Spain) under organic management. Vertical bars indicate standard error (SE) of the means. For each species, values followed by the same letter are not significantly different from each other according to Fisher's LSD multiple range test $(P \leq 0.05)$

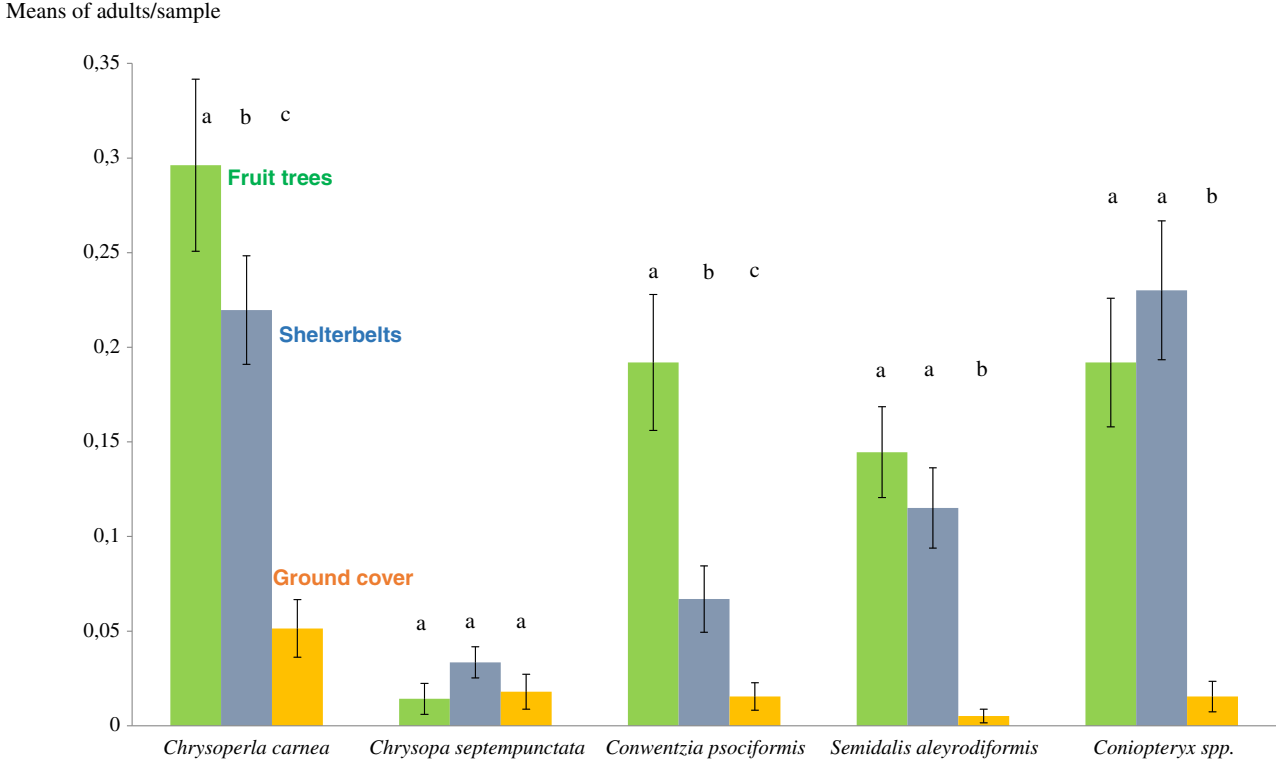

January to March) were very scarce or null which mean these species spent winter as egg or larval forms.

- $\quad$ Two species, C. psociformis and S. aleyrodiformis (two dustywings), showing an opposite trend to previous group; during winter, adult captures of these species were very high in citrus tree canopies while much lower in shelterbelts and very scarce or null at the ground vegetation level. These species had a second similar peak of captures in May but populations declined sharply during summer.

- A species, Ch. carnea, whose captures were very high during summer and autumn both in the citrus trees and in shelterbelts and very scarce during winter and beginning of spring. Seems that the more abundant Chrysopidae and Coniopterygidae share the same resources via temporal niche partitioning since when the former reach the peak of adult captures during summer captures of the later are minimum, and the opposite happens during winter.

- All Neuroptera species captured at the ground vegetation level reached the highest peak during the spring period, captures during the rest of the year being very scarce compared to the other habitats, except for Ch. septempunctata which showed a second important peak during August.

The population peaks of lacewings associated with fruit trees and shelterbelts were different in each habitat type which indicates that there was a movement of species between both habitats and shifts in the direction of predator dispersal throughout the year. Furthermore, most Neuroptera species that spent the winter period as egg or larval forms (very low number of adults between January and March) showed the same behavior; at the end of summer or beginning autumn, the adult populations associated to fruit trees declined at the time that populations within shelterbelts increased indicating these species moved there to overwinter. Adults of these species dispersed into the orchards during the following spring as can be deduced by the peaks of captures reached in May or June. These outcomes concur with other predatory insects which were found to show seasonal migration from crops to shelter habitats at different stages of their life cycle and mainly at the beginning of the cold periods to overwinter (e.g., Duelli et al. 1990; Thomas et al. 2001; Pollard and Holland 2006). However, species whose adults were active during winter, dustywings lacewings, highly preferred fruit tree canopies to spend this period. In fact, during most part of the year, adult populations of these species were abundant in citrus tree canopies and higher than in the non-crop habitats demonstrating that evergreen fruit crops can harbor predatory insects all year round. Thus, in spite of the intrinsic difficulties associated to any monoculture, some generalist predators are able to find food and shelter within the canopy of fruit trees all year round and persist from year to year within orchards.

The winter-active generalist predators play a key role on the reduction of winter pest populations, and the decline of the first seasonal population outbreaks of several agriculture pests since during early spring most natural enemies is still in dormancy or absent. This has been previously stated for other arthropod predator species which were active in fruit crops during winter (see Pekar et al. 2015). This highlights the importance of analyzing natural enemy activity over time rather than take a "snapshot" in one or few samplings which had been the most common in the bulk of the studies considering natural enemy response to agroecosystem complexity (see Chaplin-Kramer et al. 2011). 
Mean of

\section{adults / month}

a

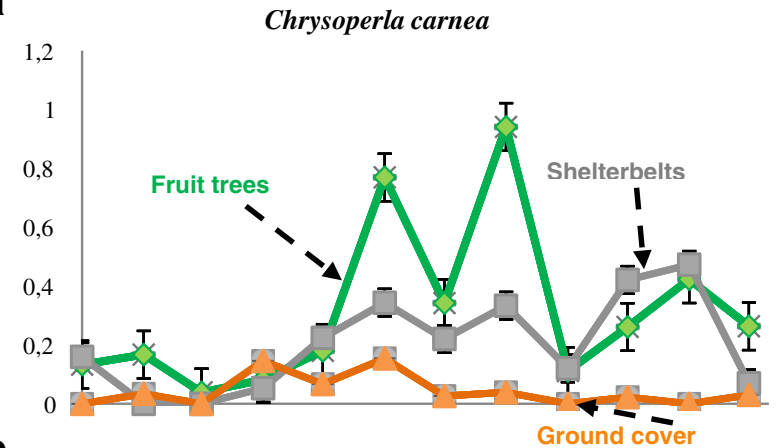

b

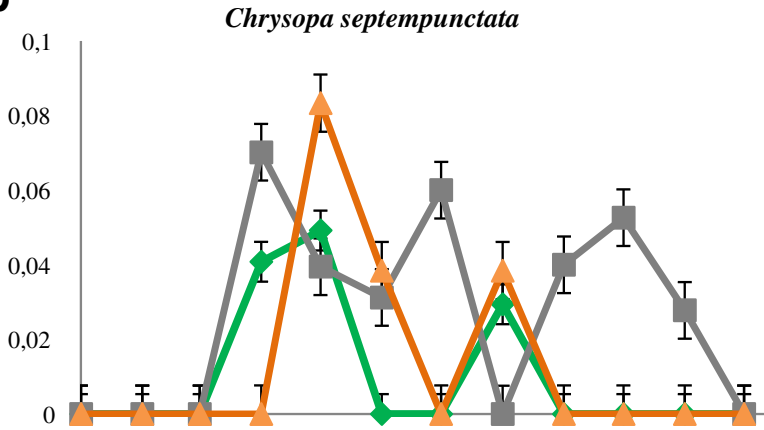

C

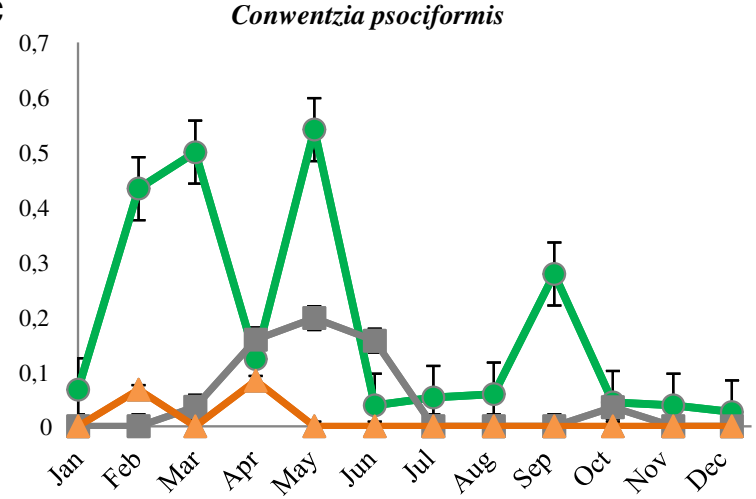

Fig. 4 a-f Population dynamics of the most abundant Neuroptera insects in fruit agroecosystems: Chrysoperla carnea, Chrysopa septempunctata, Conwentzia psociformis, Semidalis aleyrodiformis, Coniopteryx spp., and two Hemerobidae species (Micromus angulatus and Wesmaelius subnebulosus). Samples were collected

\section{Conclusion}

Although biodiversity indices were highest, as expected, within organic orchard agroecosystems, the relatively high yearround predators abundance and diversity inside sprayed tree canopies suggest that when perennial fruit trees are under conventional but not chemical-intensive treatments (such as integrated pest management programs), they can efficiently harbor predatory insects throughout the year.

Our results indicate that strategies for enhancing flying natural enemies that maximize conservation biological control, such as habitat management, should focus more on field

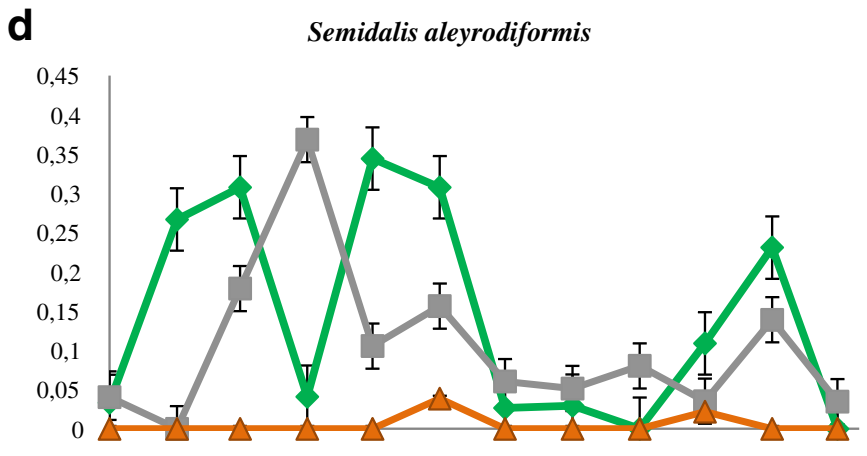

e

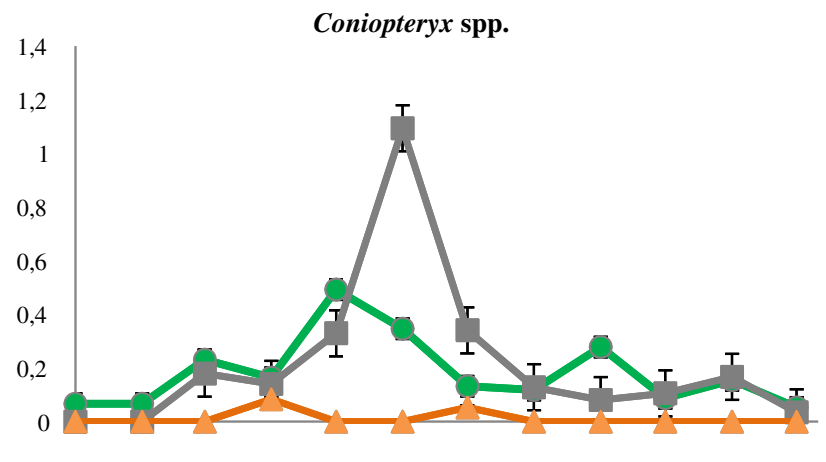

f

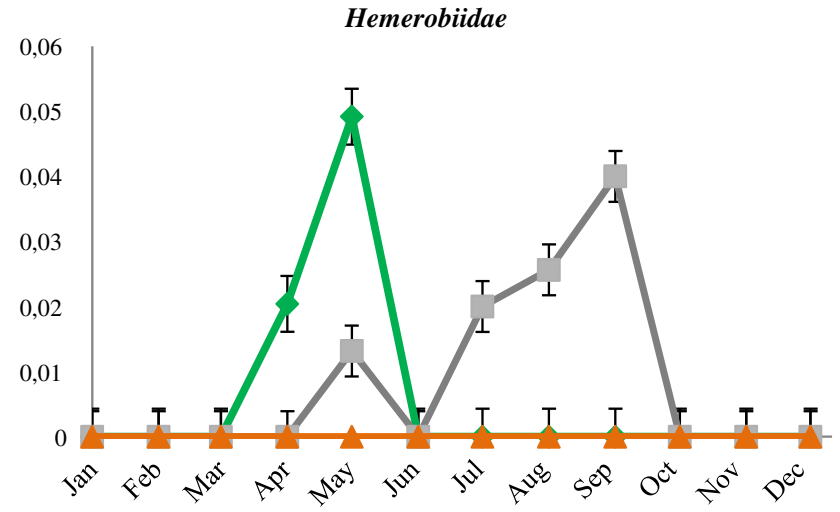

using a suction device and yellow sticky traps from 2006 to 2009 in citrus trees canopy (422 samples), shelterbelts (478 samples), and ground covers (389 samples) within 6 organic agroecosystems of eastern Spain. Vertical bars indicate standard error (SE) of the means

margin woody vegetation rather than the ground cover vegetation when considering non-crop habitats. We can say that, under Mediterranean climate conditions, flying seasonal patterns of migration from agricultural lands to non-crop habitats to overwinter depend on species adult winter activity. While dormant insects generally move to shelterbelts to overwinter, active insects remain in high proportion on fruit trees canopy. Since many flying predators move from crop towards surrounding shelterbelts to overwinter, presence of boundary woody vegetation can avoid their migrations to other areas. Shelterbelts serve to attract flying predators to the farmland and maximize survival possibilities when a perturbation 
occurs, allowing them to quickly re-colonize the crop afterwards. More studies to address which particular shrubs or trees species that can be used to build shelterbelts are the more suitable to harbor this, and other key predatory insect orders are needed.

Acknowledgments We thank two anonymous reviewers and the editors for constructive comments on the manuscript. The authors are very grateful to Rosa Guaita, Pili Mañó, Anna Marco, Altea Calabuig, Bernadette Csőke, and Adela Cuesta for their help and collaboration with laboratory and field work and to citrus orchards owners who permitted access for this study. Joan van Baaren and Ferran Garcia-Marí provided valuable comments that improved the manuscript. We thank Lucy Alford and Adrien Bonvin for language corrections.

\section{References}

Altieri MA, Letourneau DK (1982) Vegetation management and biological control in agroecosystems. Crop Prot 1:405-430. doi:10.1016/02612194(82)90023-0

Altieri MA, Schmidt LL (1986) The dynamics of colonizing arthropod communities at the interface of abandoned, organic and commercial apple orchards and adjacent woodland habitats. Agric Ecosyst Environ 16:29-43. doi:10.1016/0167-8809(86)90073-3

Bengtsson J, Ahnström J, Weibull A (2005) The effects of organic agriculture on biodiversity and abundance: a meta-analysis. J App Ecol 42:261-269. doi:10.1111/j.1365-2664.2005.01005.x

Bianchi F, Booij CJH, Tscharntke T (2006) Sustainable pest regulation in agricultural landscapes: a review on landscape composition, biodiversity and natural pest control. Proc R Soc B 273:1715-1727. doi: 10.1098/rspb.2006.3530

Chaplin-Kramer RM, Rourke E, Blitzer EJ, Kremen C (2011) A metaanalysis of crop pest and natural enemy response to landscape complexity. Ecol Lett 14:922-932. doi:10.1111/j.1461-0248.2011. 01642.x

Crowder DW, Northfield TD, Strand MR, Snyder WE (2010) Organic agriculture promotes evenness and natural pest control. Nature 466: 109-112. doi:10.1038/nature09183

Dogramaci M, DeBano SJ, Kimoto C, Wooster DE (2011) A backpackmounted suction apparatus for collecting arthropods from various habitats and vegetation. Entomol Exp et Appl 139:86-90. doi:10. 1111/j.1570-7458.2011.01099.x

Duelli P, Studer M, Marchland I, Jakob S (1990) Population movements of arthropods between natural and cultivated areas. Biol Conserv 54: 193-207. doi:10.1016/0006-3207(90)90051-P

Eilenberg J, Hajek A, Lomer C (2001) Suggestions for unifying the terminology in biological control. BioControl 46:387-400. doi:10.1023/A:1014193329979

Forman RTT, Baudry J (1984) Hedgerows and hedgerow networks in landscape ecology. Environ Manage 8:495-510. doi:10.1007/ BF01871575

Gurr GM, Wratten SD, Luna JM (2003) Multi-function agricultural biodiversity: pest management and other benefits. Basic Appl Ecol 4:107-116. doi:10.1078/1439-1791-00122
Hole DG, Perkins AJ et al (2005) Does organic farming benefit biodiversity? Biol Conserv 122:113-130. doi:10.1016/j.biocon.2004.07.018

Landis DA, Wratten SD, Gurr GM (2000) Habitat management to conserve natural enemies of arthropod pests in agriculture. Annu Rev Entomol 45:175-201. doi:10.1146/annurev.ento.45.1.175

Long RF, Corbett A, Lamb C, Reberg-Horton C, Chandler J, Stimmann M (1998) Beneficial insects move from flowering plants to nearby crops. Calif Agr 52:23-26. doi:10.3733/ca.v052n05p23

Östman Ö, Ekbom B, Bengtsson J (2001) Landscape heterogeneity and farming practice influence biological control. Basic App Ecol 2: 365-371. doi:10.1078/1439-1791-00072

Pantaleoni RA, Ticchiati V (1988) I Neurotteri delle colture agrarie: osservazioni sulle fluttuazioni stagionali di populazione in frutteti. Boll dell'Ist di Entomol 43:43-57

Panzer R, Schwartz MW (1998) Effectiveness of a vegetation-based approach to insect conservation. Conserv Biol 12:693-702. doi:10.1111/j.1523-1739.1998.97051.x

Paredes D, Cayuela L, Gurr G, Campos M (2013) Effect of non-crop vegetation types on conservation biological control of pests in olive groves. PeerJ 1:1-16. doi:10.7717/peerj.116

Pekar S, Michalko R, Loverre P, Líznarová E, Cernecká L (2015) Biological control in winter: novel evidence for the importance of generalist predators. J Appl Ecol 52:270-279. doi:10.1111/13652664.12363

Pollard KA, Holland JM (2006) Arthropods within the woody element of hedgerows and their distribution pattern. Agric Forest Entomol 8: 203-211. doi:10.1111/j.1461-9563.2006.00297.x

Rand TA, Tylianakis JM, Tscharntke T (2006) Spillover edge effects: the dispersal of agriculturally subsidized insect natural enemies into adjacent natural habitats. Ecol Lett 9:603-614. doi:10.1111/j.14610248.2006.00911.x

Silva EB, Franco JC, Vasconcelos T, Branco M (2010) Effect of ground cover vegetation on the abundance and diversity of beneficial arthropods in citrus orchards. Bull Entomol Res 100:489-499. doi:10.1017/S0007485309990526

Smukler SM, Sánchez-Moreno S et al (2010) Biodiversity and multiple ecosystem functions in an organic farmscape. Agric Ecosyst Environ 139:80-97. doi:10.1016/j.agee.2010.07.004

Stelzl M, Devetak D (1999) Neuroptera in agricultural ecosystems. Agric Ecosyst Environ 74:305-321. doi:10.1016/S0167-8809(99)00040-7

Straub CS, Finke DL, Snyder WE (2008) Are the conservation of natural enemy biodiversity and biological control compatible goals? Biol Control 45:225-237. doi:10.1016/j.biocontrol.2007.05.013

Thierry D, Deutsch B, Paulian M, Villenave J, Canard M (2005) Typifying ecosystems by using green lacewing assemblages. Agron Sustain Dev 25:473-479. doi:10.1051/agro:2005047

Thomas CFG, Parkinson L, Griffiths GJK, García AF, Marshall EJP (2001) Aggregation and temporal stability of carabid beetle distributions in field and hedgerow habitats. J App Ecol 38:100-116. doi: 10.1046/j.1365-2664.2001.00574.x

Villenave J, Thierry D, Mamun A, Lode T, Rat-Morris E (2005) The pollens consumed by common green lacewings Chrysoperla spp. in cabbage crop environment in western France. Eur J Entomol 02: 547-552, 10.14411/eje.2005.078

You M, Hou Y, Liu Y, Yang G, Li Z, Cai H (2004) Non-crop habitat manipulation and integrated pest management in agroecosystems. Acta Entomol Sinica 47:260-268 (http://www.insect.org.cn/EN/ Y2004/V47/I2/260) 